\title{
FIFTEEN YEARS OF OPERATION AT NASA'S NATIONAL TRANSONIC FACILITY WITH THE WORLD'S LARGEST ADJUSTABLE SPEED DRIVE
}

\author{
G. Sydnor, PE*; R. Bhatia, Fellow IEEE ${ }^{\dagger}$; H. Krattiger, Member IEEE ${ }^{+}$; J. Mylius ; D. Schafer ${ }^{\alpha}$ \\ *NASA, Investment Manager, Aeronautics Test Program, ARMD, Hampton, Va, USA \\ ${ }^{\dagger} A B B$, Medium Voltage Drives Project Manager, New Berlin, Wi, USA \\ ${ }^{+}$ABB, Director, Business Development, New Berlin, Wi, USA \\ ${ }^{\circ} A B B, M V$ Power Converter Systems Sales Manager, Turgi, Switzerland \\ ${ }^{\alpha}$ Energie Wasser Bern, CEO, Berne, Switzerland
}

Keywords: Load Commutated Inverter, Adjustable Speed Drive, Harmonic Filter, Operating Experience, Lessons Learned

\begin{abstract}
In September 1995, a project was initiated to replace the existing drive line at NASA's most unique transonic wind tunnel, the National Transonic Facility (NTF), with a single 101 MW synchronous motor driven by a Load Commutated Inverter (LCI). This Adjustable Speed Drive (ASD) system also included a custom four-winding transformer, harmonic filter, exciter, switchgear, control system, and feeder cable. The complete system requirements and design details have previously been presented and published [1], as well as the commissioning and acceptance test results [2]. The NTF was returned to service in December 1997 with the new drive system powering the fan. Today, this installation still represents the world's largest horizontal single motor/drive combination. This paper describes some significant events that occurred with the drive system during the first 15 years of service. These noteworthy issues are analyzed and root causes presented. Improvements that have substantially increased the long term viability of the system are given.
\end{abstract}

\subsection{Introduction}

NASA's NTF is a closed loop, continuous flow wind tunnel that uses a high power ASD system to spin the circulating fan, as shown in Figure 1. This high Reynolds number, cryogenic test facility is located at the Langley Research Center in Hampton, Virginia, and is widely used by the aircraft industry to simulate the full scale, in-flight performance characteristics of large transport aircraft at transonic speeds. NTF is unique because it can match cruise flight Mach number and simulate the corresponding high altitude Reynolds number. This feature is very important to aircraft designers, as it directly affects aircraft stability and fuel consumption/passenger mile. The NTF is one of two wind tunnels in the world that can achieve the high Reynolds number testing capability, and the only tunnel that can simulate Reynolds numbers in excess of 100 million [3].

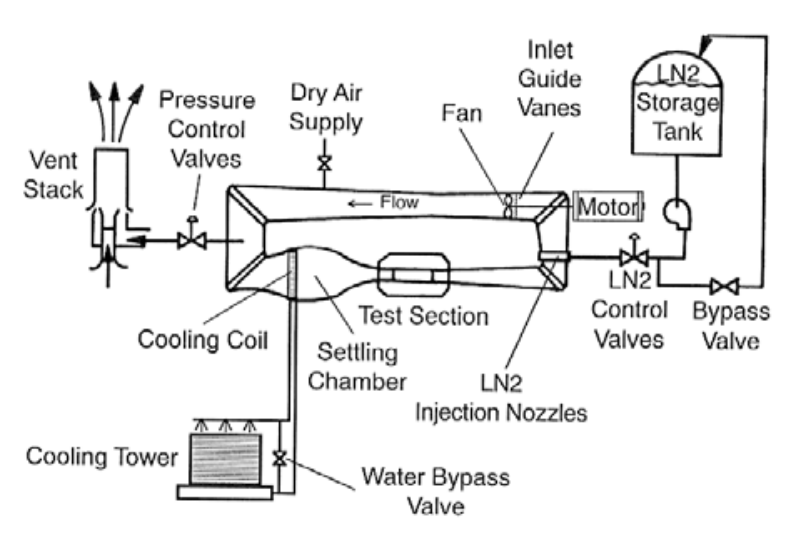

Figure 1: Diagram of the National Transonic Facility.

To reach these conditions, the tunnel uses cryogenic nitrogen gas at very low temperature and high density. With the tunnel circuit pressurized to several atmospheres, the power required to circulate this low temperature, high pressure gas can reach a maximum of 135,000 horsepower. The original complex, aging drive line required significant maintenance and caused substantial downtime. The electromechanical speed control system was shared with another transonic tunnel; at times limiting the power for the NTF as shown in Figure 2.

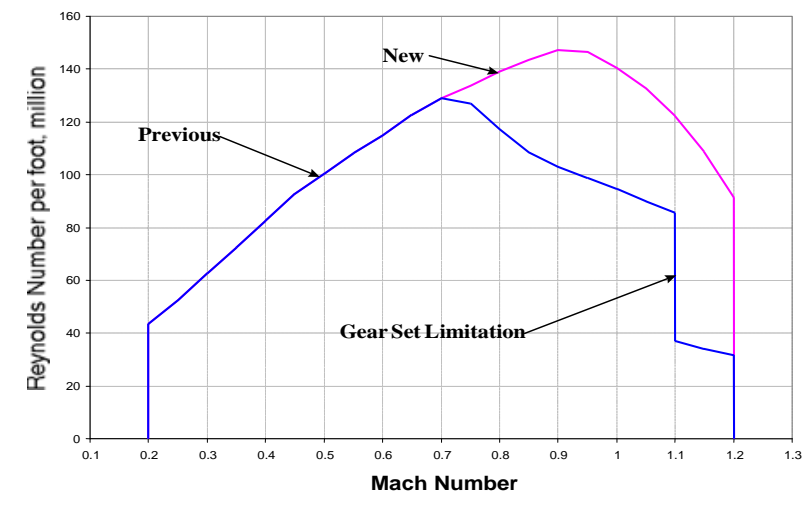

Figure 2: NTF Mach Number vs. Reynolds Number envelope. 


\subsection{Drive System Overview}

Because the wind tunnel must operate at varying Mach and Reynolds numbers, fan speed control is a crucial requirement. Electronic control of high power devices driving a synchronous motor is an ideal solution to meet this requirement. Power levels up to $60 \mathrm{MW}$ are typical in industry; however, the $101 \mathrm{MW}$ required for the NTF make this the largest adjustable speed drive system to date in the world and on a comparable scale with global hydro-electric pumped storage facilities. The flexibility of a completely variable speed drive system coupled to a wind tunnel has proven very successful by expanding NASA's research capabilities for the nation. With improved acceleration, deceleration, reliability, speed control and operating envelope over the old drive line, the facility has been able to provide users a wide variety of test conditions and efficiencies that are both cost effective and performance enhancing.

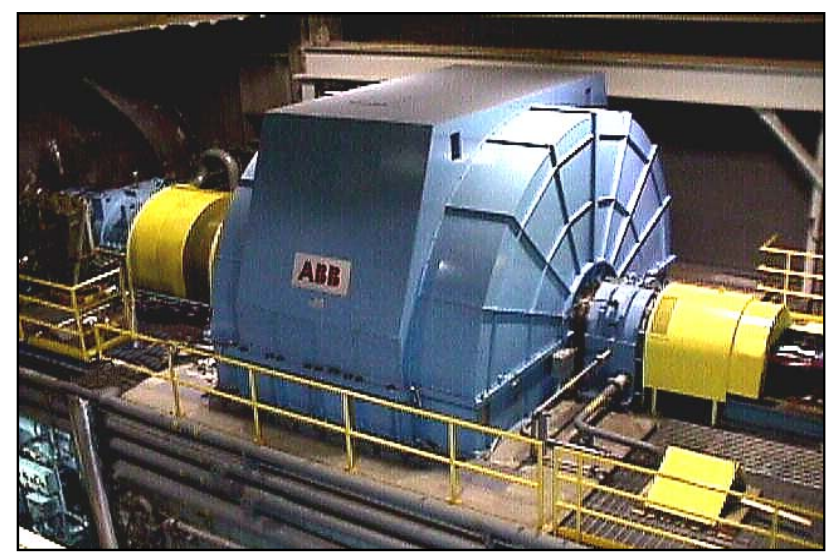

Figure 3: The installed 101 MW NTF Drive Motor.

The ASD system configuration contains a high-voltage, four winding, step down isolation transformer feeding a Load Commutated Inverter frequency converter with two-channel 12/12-pulse connections feeding two separate synchronous motor stator windings as shown in Figure 4.

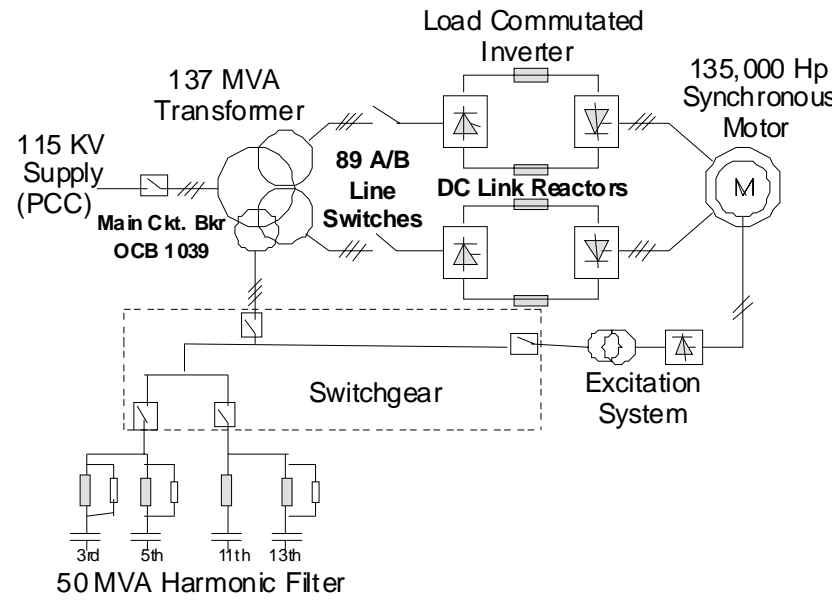

The LCI converter takes power from the supply network at constant voltage and frequency, and converts it to variable voltage and frequency feeding the synchronous motor. The synchronous machine can be accelerated (motor mode) and decelerated (generator mode) at any speed within the operating speed range of the NTF fan shown in Figure 5.

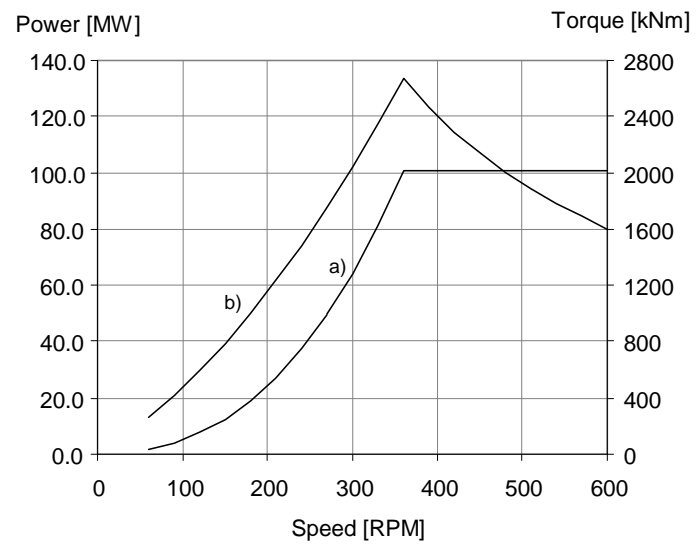

Figure 5: NTF fan requirements; a) shaft power, b) torque.

The major components of the ASD are:

1. Synchronous motor

2. LCI converter (power electronics + control system)

3. Converter transformer

4. Harmonic filter

5. Switchgear

\subsection{Synchronous Motor}

The synchronous motor is a 12-pulse type with two stator winding systems. The motor was designed with a $30^{\circ}$ electrical phase-shift between the two stator windings, so that pulsating torques are reduced. This provides a relative reduction of the mechanical stress on the shaft train and minimized flow pulsations. Each motor stator winding uses a two layer, Roebel bar winding system in the circumferential slots. The rotor is a forged hub with conical shaft ends specially designed for this application. The entire installation was accomplished in three separate lifts: lower stator, rotor, and finally the upper stator. The end windings needed between the upper and lower halves were field connected and the entire machine tested once fully assembled. The end bells were made in two halves, with the upper section easily removable for inspections. The installed motor is shown in Figure 3.

The cooling of the machine is provided by a water to air heat exchanger circulated by blower fans in a closed housing. The operation of these fans is controlled depending on the load of the motor. The motor bearings are mounted on the same foundation frame as the stator frame and are of the tilting pad type with pressure oil injection for low speeds. In order to limit the mechanical stress in the existing shaft line, a torque limiting device is integrated into the coupling. Figure 6 shows general layout of the synchronous motor.

Figure 4: Single line diagram of the NTF drive system. 


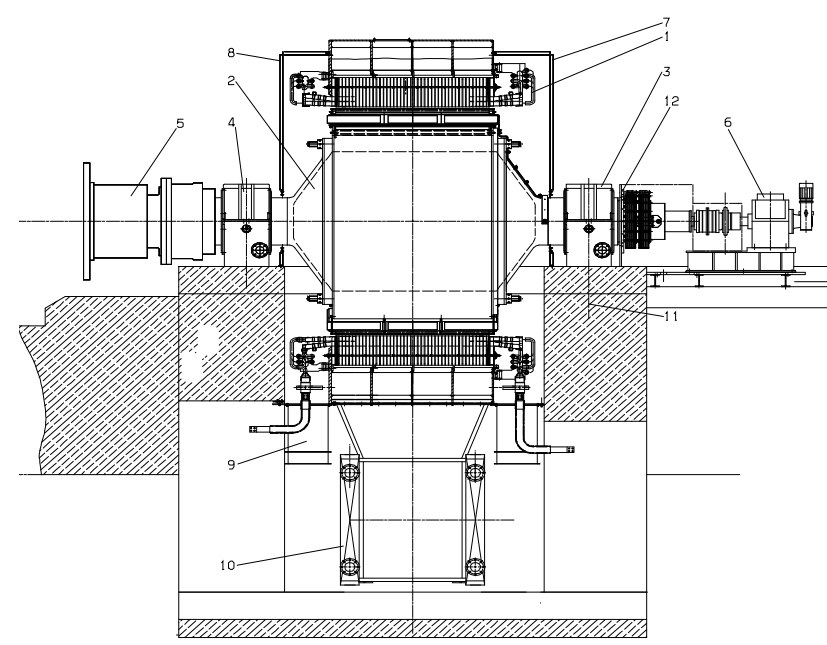

Figure 6: General layout of the synchronous motor - 1) stator winding; 2) rotor shaft ends; 3) NDE bearing; 4) DE bearing; 5) torque limiting device; 6) turning gear device; 7/8) stator covers; 9) motor driven fans; 10) air to water heat exchanger; 11) foundation frame; 12) slip rings.

\subsection{Load Commutated Inverter}

The power part of the LCI converter consists of two independent 6/6-pulse channels, resulting in a total of 4 identical three-phase bridges. Each bridge has 6 branches with 12 series-connected thyristors; each thyristor is rated at 5200 volts repetitive reverse/direct voltage; one thyristor per branch is redundant (' $n+1$ ' design). In case of one thyristor failure per branch, the ASD is able to run at full load continuously. Both the line-side and the motor-side converters can operate as rectifier or inverter, therefore the machine can operate as motor (driving mode) or generator (braking mode). The thyristors are cooled by an internal deionized water circuit supplied from a separate skid. The converter efficiency at full load is better than $99 \%$.

\subsection{Converter Transformer}

The LCI matching transformer is a four-winding, oil cooled unit designed and manufactured specifically for this application. The unit is an outdoor, mineral oil insulated, with forced oil and air cooling. The transformer takes the incoming Center electricity from a pressurized gas underground cable and steps it down through two LCI-power windings and a tertiary winding for auxiliaries and harmonic filtering. The transformer is rated at 137 MVA with 115/13.4/13.4/13.8kV voltages respectively.

\subsection{Harmonic Filter}

The harmonic filter was designed to meet the NASA requirements for line power factor and harmonic distortion. The filter is connected to the tertiary winding of the converter transformer with a fundamental power of 50 MVAR split into four series-resonant circuits tuned to the 3rd, 5th, 11th and 13th harmonic frequencies. In all operating conditions the power factor is above 0.90 lagging and harmonic distortion is below the recommended IEEE 519 [4] Total Harmonic Distortion (THD) limits shown in Table 1. The harmonic filter consists of four metal enclosed outdoor units, weighing over 25,000\# each. The filters are series reactors tuned with internally fused capacitors and damping resistors. The 3/5 harmonic filters use iron core reactor, as the required design impedance and power level for these two filter banks precluded using air core reactors in the enclosed filter banks. The 11/13 filters use air core reactors. All units include fan cooling.

\begin{tabular}{cccc}
\hline $\begin{array}{c}\text { Shaft Power } \\
{[\mathrm{HP}]}\end{array}$ & $\begin{array}{c}\text { Speed } \\
{[\mathrm{RPM}]}\end{array}$ & $\begin{array}{c}\text { THD } \\
{[\%]}\end{array}$ & $\begin{array}{c}\text { LIMIT IEEE 519 [4] } \\
{[\%]}\end{array}$ \\
\hline 25000 & 180 & 1.4 & 2.5 \\
50000 & 240 & 1.7 & 2.5 \\
86000 & 300 & 1.3 & 2.5 \\
135000 & 360 & 1.1 & 2.5 \\
135000 & 480 & 1.1 & 2.5 \\
135000 & 600 & 1.1 & 2.5 \\
\hline
\end{tabular}

Table 1: Voltage Distortion at the Point of Common Coupling

\subsection{Switchgear}

A metal enclosed, outdoor switchgear line up provides space for two line switches, protective relaying, and four system breakers. The relaying and isolator section houses two motor operated line switches, each rated at 3000A, 15kv. Each line switch connects a secondary winding of the converter transformer to a single 6-pulse LCI inverter bridge. The breaker cubicles consist of metal clad vacuum breakers for main (3000A), harmonic filters (2000A), and field excitation transformer (1200A). Figure 7 shows the relative layout in the switchyard of the transformer, harmonic filters, and switchgear, respectively from left to right.

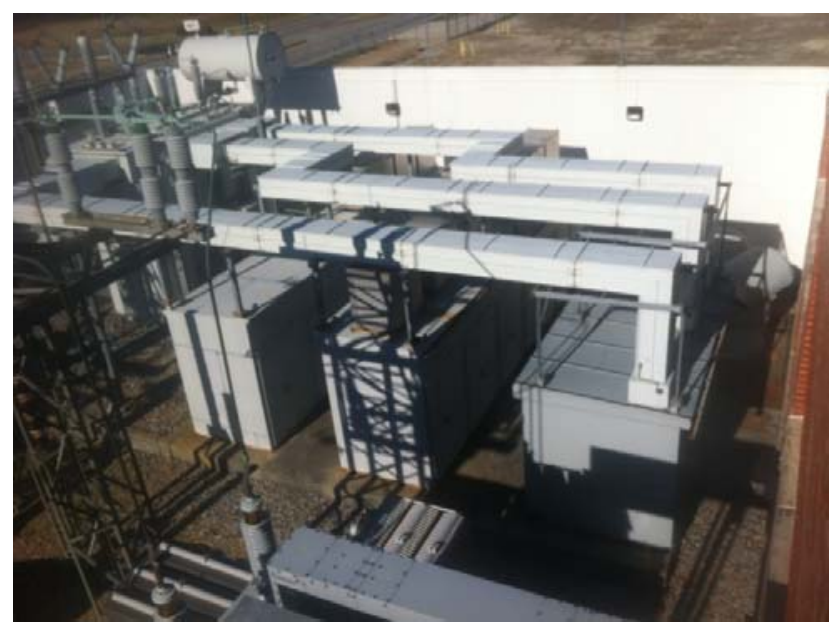

Figure 7: Switchyard layout for the NTF drive system.

\subsection{Operational Experience}

The duty cycle of the drive system at the National Transonic Facility is not continuous. The nature of closed-circuit wind tunnel testing requires constant model adjustments and 
change outs. Therefore, the drive system has to be started and stopped many times in a given test program. This requirement was factored into the system specifications "The drive system shall be designed for 20 full load $600 \mathrm{rpm}$ drive starts and 20 drive stops in a 24 hour period.” [5]. When personnel entry into the wind tunnel test section is required, the drive system must be completely isolated from all electrical power. This requires opening the stator side line isolation switches between the transformer and LCI as well as the excitation system and harmonic filter breakers. Historical data from the facility logs have shown that the facility has an average of 2.3 start/stop cycles per hour of on-line operation [6] Since the system has been installed, the transformer has been energized over 100,000 hours, the LCI for 16,200 hours, and the drive motor for 7,200 hours (fan on hours). While these are relatively few operational hours, the breaker cycles are in excess of 3000 and the system has withstood many start-stop transients.

The following sections outline selected noteworthy events that have occurred over the last fifteen years. The facility keeps a well-documented log of issues via Problem/Failure Reports (PFR), Task/Test Reports (TTR) and daily logs of research notes. By researching these documents and personal experience with several of the major issues, the authors present several problems, root causes, and lessons learned.

\subsection{Synchronous Motor}

\subsubsection{Motor Rotor Ground Fault}

a. Problem - In April 2005 the drive system experienced the first of several trips initiated by the rotor ground fault sensing circuit. When investigated, a ground fault path was not present from the rotor and the excitation ground fault relay could be reset. The drive system tripped off several more times in April. Cleaning and tightening maintenance was conducted on the slip-ring area up to the end bell, however another trip occurred in May. At that time, the drive was shut down until the system provider could be brought in to troubleshoot the problem. Additional runs were made under the supervision of the service engineer, and the ground fault relay was determined to be operating satisfactorily. The rotor/connections was highly suspect as the faults were associated with high rpm operation. The drive end (DE) bell was removed and the rotor connections were inspected. The copper bars that fed power to the field poles on the rotor cone were unsupported. Several bolts were missing and supporting insulators were damaged along the rotor interconnection bars and backing sections between the pole pieces. Pieces of the broken bolts had fallen into the rotor poles and stator end windings.

b. Root Cause - The root cause of the failure was determined to be thermal and rotational overload stress on the retaining bolts and insulators holding the DC interconnection bars to the outer surface of the rotor shaft. The original design of the motor did not take into account the correct loads for the fasteners. The tolerance of the insulator/retaining bolt fit to the copper bar did not allow room for growth, crushing the insulator and putting addition stress in the retaining bolts. Once the first bolt fatigued, the remaining bolts gave way.

c. Solution - New insulators were manufactured with sufficient room for the copper to flex. The interconnection bars were secured with a higher strength bolt. The damaged areas of the rotor and stator were cleaned and reinsulated.

d. Lesson Learned- Design of rotating components must include all load conditions and factors including ambient conditions and effects or rotating weight. Know what the safety factors are!

\subsubsection{Pole Piece Interconnection Delamination}

a. Problem - In August 2006 the drive system experienced a trip on the rotor ground fault sensing circuit. The back lamination of a short, unwrapped rotor pole connection began to peel away starting at the leading edge of the connection until the delamination contacted the rotor surface. The tear was approximately $2 / 3$ of the width of the connection and along the interface with the bolted connection, as shown in Figure 8. The motor was operating at $600 \mathrm{rpm}$ at the time of the trip. It did not tear off completely since the motor tripped offline as soon as the delaminated section contacted the rotor surface. There was evidence that several other unwrapped pole connections had signs of delamination and tears. The delamination is shown in Figure 8.

b. Root Cause - The short laminated copper connection to the pole pieces were not originally taped. These were initially thought to be sufficiently strong without additional wrapping. As the connections flexed at high speed, air was forced in between the laminations causing vibration that led to fatigue concentrated at the fixed ends of the connections.

c. Solution - The system provider recommended to cut off the delaminated portion and wrap the damaged portion with glass tape, epoxy coat, and cure. All other connections were glasstape wrapped, epoxy coated, and cured for 16 hours.

d. Lesson Learned - Laminated copper connections exposed to high speed cross flow air need to be secured with tape and epoxy to prevent vibration fatigue, regardless of length.

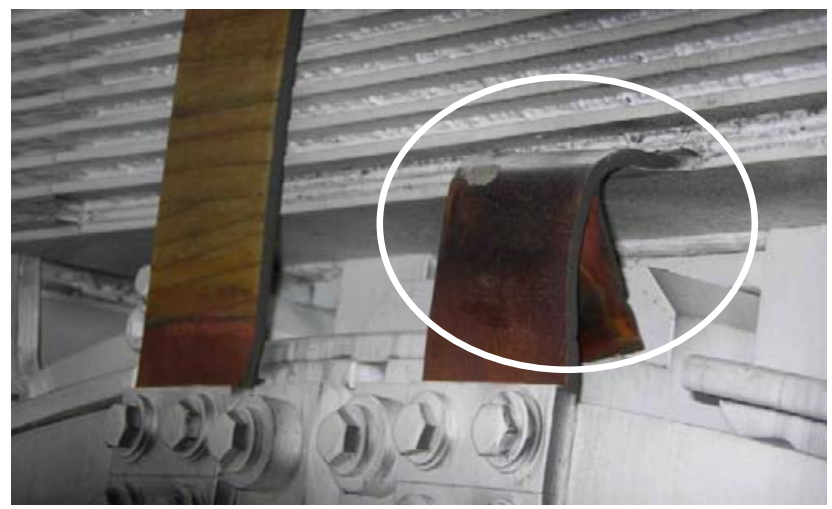

Figure 8: Rotor pole piece flexible connection delamination. 


\subsection{Load Commutated Inverter}

\subsubsection{Link Reactor Eddy Current}

a. Problem - During a routine inspection of the LCI equipment in September 2001, maintenance personnel observed burn marks at each of the four DC link reactors. The four large air core reactors are water cooled and mounted above the thyristor power stacks in the LCI enclosure. Figure 9 shows the insulated corner of the reactor base frame heated from eddy current flow though the floor grating.

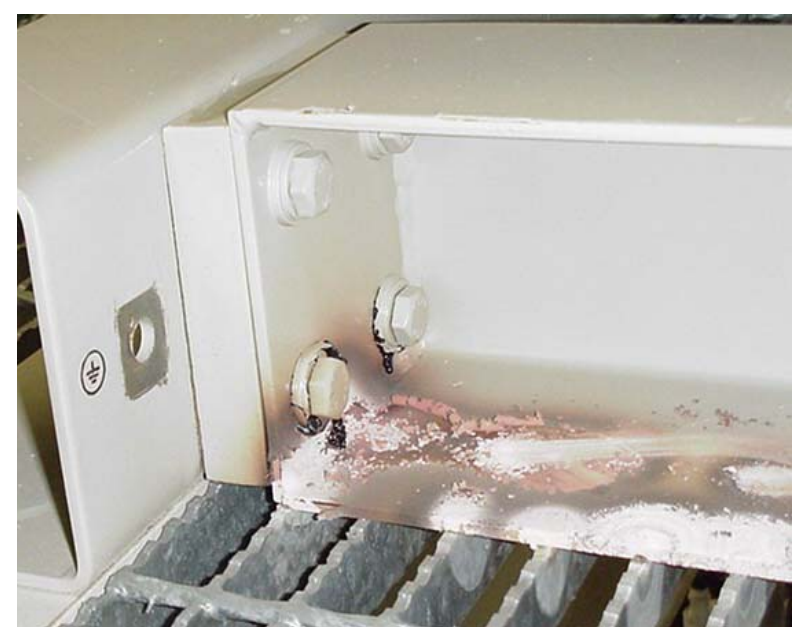

Figure 9: Eddy current damage on reactor frame.

b. Root Cause - Detailed examination of the burn areas and steel connections confirmed that an eddy current flow path had been established through the base frame of the reactor and the steel grid decking to which it was bolted. In this closed loop, the magnetic flux, caused by the ripple current superimposed to the direct current inside the winding, induced a voltage that caused high current flow. While no alarms had occurred and the drive system was fully functional, the anomaly was corrected as soon as practical.

c. Solution - The system provider and link reactor manufacturer were notified of the problem. The solution was to add fiberglass insulators beneath the reactor frames elevating the units off the steel grid approximately one inch, breaking the eddy current circuit path. This raised the relative height of the cooling water connections. To accommodate this new complication, the cooling water system was drained and flanged pipe spacers to match the new height to the existing cooling water piping were installed. Once the modifications were completed, there were no further issues with eddy current damage.

d. Lesson Learned - While the reactors were properly designed with open magnetic circuit bases, this was thwarted by mounting the frames directly to the steel decking. Installation details must be included in the design phase to assure that equipment works as intended once installed. Construction inspection provides the owner quality assurance that the design is being correctly implemented.

\subsubsection{Control Voltage Power Supply}

a. Problem - In February 1999, the 24 vdc power supply for the thyristor firing and monitoring racks failed. This power supply included a voltage sensitive relay, such that thyristors firing is inhibited if the power supply output voltage falls below 20 volts. This feature 'protects' the thyristors from incorrectly firing when control voltage is lost. The ASD shut down in an orderly manner when this power supply failed. Without a spare, a generic power supply without this relay protection was temporarily installed in order to continue research testing. After several days of operation, this power supply also failed and a violent shutdown of the ASD occurred.

b. Root Cause - Without the power supply sensing protection circuit, the LCI control software did not know the power supply had failed. The control system could not close the firing window to the conducting thyristors and two phases per bridge were left turned on. This condition caused a phase to phase short circuit overcurrent and consequently tripped the main circuit breaker. The high overcurrent flow shorted 16 thyristors, causing a severe shock throughout the motor and foundation.

c. Solution - The system supplier shipped a new power supply to replace the defective one, and a spare unit, to preclude a future failure from causing downtime or system damage. In addition, 16 thyristors were shipped to replace the defective ones. After a thorough inspection, no other system or structural damage was found. The technicians were trained with regard to the criticality of the power supply interlocks within the LCI.

d. Lesson Learned - Replacement parts must be suitable for the application requirements. Temporary fixes have risks that should be evaluated by probability and consequences. All parties should understand and accept the risks prior to operation. Spare part inventories should include low cost, critical components. This event could have been a catastrophic failure for the drive and motor foundation.

\subsubsection{Heat Exchanger}

a. Problem - The LCI was designed with a separate closed loop cooling skid to remove the heat generated by the losses in the converter stacks. The primary de-ionized cooling water loop uses a water to water heat exchanger (HEX) to reject the thyristor heat losses into the facility's centralized cooling water system. With an overall converter efficiency of 99\%, the losses are relatively small, but at $101 \mathrm{MW}$ operation, this equates to 1 megawatt of heat to be removed. Over time, the pressure drop across the heat exchanger gradually rose, until in 2006, sufficient cooling was not achievable.

b. Root Cause - The excessive pressure drop across the HEX was a result of gradual clogging in the circulating paths from foreign material entrained by the open-air cooling tower. The 
tower is constantly entraining dust from an adjacent busy highway and pollen from the local flora.

c. Solution - The existing cooling water system has a $50 \mathrm{MW}$ capacity, and is used for all facility cooling needs. A sand filter system for this large cooling tower would be cost prohibitive. The other cooling circuits at the facility are not as sensitive to the material build-up as the small LCI heat exchanger. In lieu of providing a smaller filtering system, the decision was made to keep a spare HEX and monitor the pressure drop on the LCI cooling system.

d. Lesson Learned - Existing utilities are often assumed to be available for retrofit or new installation upgrades during the conceptual and design phases of a project. Operational characteristics of these existing subsystems must be fully understood to assure successful support of new capabilities. Responsibility for determining these can be specified to the system provider.

\subsection{4 'Low Voltage’ Undervoltage}

a. Problem - As the drive system was beginning regular operations in early 1998, an intermittent condition arose where seemingly random low voltage alarm and trips would occur on the LCI. The anomaly started by triggering the low voltage alarm on the 480 vac motor control center, MCC3, voltage monitoring relay. Since the LCI control power was fed from MCC3, subsequently an alarm and trip of the LCI on "Low Voltage Undervoltage" would occur. The event would only happen with the tunnel in cryogenic mode (using liquid nitrogen) and the drive system on line. From the facility datalogger, further correlation was made between energizing one particular liquid nitrogen pump and the trip event.

b. Root Cause - The liquid nitrogen pump in question, "P1", was driven by a $100 \mathrm{Hp}$ induction motor which starts across the line with no inrush current limiting features. The pump and MCC3 were fed from the same upstream transformer. A recording was made of the MCC3 bus voltage during a P1 pump start as shown in Figure 10. The voltage dropped 8\% for 5 seconds, sufficiently low enough and long enough to trigger a low voltage trip on the LCI. This test was made independently of any other loads on the bus, so the actual dip was probably lower.

c. Solution - The parameters in the LCI control were changed to increase the allowable voltage dip and time duration. No further incidents occurred with undervoltage conditions on the LCI. A higher tap setting was connected on the secondary side of the step down control voltage transformer internal to the LCI minimizing the sensitivity to undervoltage conditions.

d. Lesson Learned - If existing utilities will be used to provide support for new installations or upgrades, full characterization, including transient conditions have to be understood.

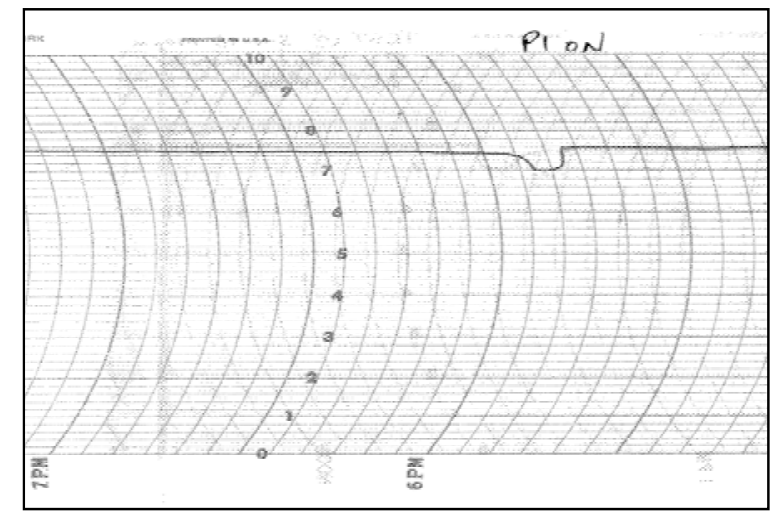

Figure 10: 480 vac voltage dip at MCC3 when starting P1.

\subsubsection{Field Excitation Cooling Anomaly}

a. Problem - In early 1999, intermittent trips were occurring on the Field Excitation control system immediately after the drive was commanded on. Sequence data indicated that the processor chassis cooling fans were not operational, however, by observation they were running. The cooling fan air flow switches were bypassed confirming that the dampers were not maintaining an 'open' position once the fans were energized.

b. Root Cause - There was insufficient air flow to maintain the open position of the dampers until sufficient air flow was established through the entire chassis. Without the dampers holding in the flow position, the flow indicating switches were not satisfied.

c. Solution - Increase the delay timer on loss of cooling flow trip condition.

d. Lesson Learned - Time delays have to be appropriately set for realist operation, not based on theoretical performance. Too much sensitivity generates false alarms and nuisance trips.

\subsection{Converter Transformer}

There have been no problems with the transformer operation.

\subsection{Harmonic Filter}

\subsubsection{Reactor Failure - Manufacturing Defect}

a. Problem - In early 1998 the drive system experienced two separate failures in the harmonic filter. The first failure involved a melt-down of the phase $C$ reactor on the $3^{\text {rd }}$ harmonic filter. There were no spares on hand. Because the facility was involved in a critical research test, the system provider was contacted regarding operational limits without the third harmonic filter so that testing could continue. This resulted in a set of operational curves defining all filter bank combinations and corresponding maximum load conditions. The load cases were constrained by overload of the remaining connected filter components, overload of the power provider's 
upstream capacitor bank, and limitation of the voltage distortion at PCC to 3\% [7]. Figure 11 shows the reduction in power for the case without the third harmonic filter. The drive was reconfigured to operate without the filter, and fortunately, the test conditions were within the operating envelope allowed by the system provider. Once the replacement reactor was fabricated and installed, system operation returned to normal.

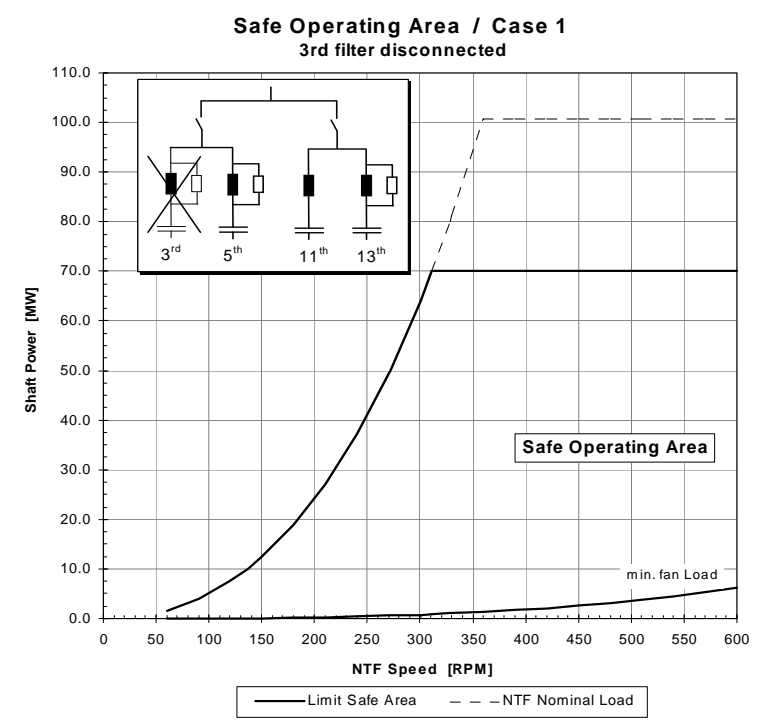

Figure 11: Reduced load envelope without the $3^{\text {rd }}$ harmonic filter energized.

The second failure, three months later, involved a similar failure of the phase A reactor on the $5^{\text {th }}$ harmonic filter. Again the system was reconfigured with the failed harmonic filter taken out of operation because there were no spares available. However, the power level permitted for operation was so low that all research test conditions could not be met.

$b$. Root Cause - After the second filter failure, a great deal of attention was placed on the reactor vendor to explain the root cause of the failure. All six iron core reactors were manufactured by the same vendor. At first the vendor could not identify any defect that would relate to the failure of the units. After further investigation, the vendor finally determined the root cause of the problem. The reactor's center core installation process had recently started using a new type of epoxy that was not fully cured during manufacturing. This epoxy would reflow at high operating temperatures, allowing the core to shift, changing the inductance of the reactor. As the inductance changed, more current flowed, inducing a thermal runaway in the reactor.

c. Solution - The vendor changed the epoxy materials, installed different pumping and mixing equipment, and improved gapping in the center core to allow free flow of epoxy fully surrounding the steel shunts. The vendor also agreed to provide a complete set of six new reactors and in August 1998, the system provider completed the installation under warranty. The change out actually proved to be very challenging, because the overhead bus duct and damping resistors prevented easy access to the reactor locations, as shown in Figure 7.

d. Lesson Learned - Perseverance is required to get to the root cause of some problems. Had the vendor not taken the effort and time to carefully examine the manufacturing process and determined the failure mode, additional reactors would have eventually failed one by one.

Always consider the maintenance and repair access when installing heavy or complex equipment in congested areas. Highly integrated efficient use of real estate can be attractive until something has to be extracted from the internal areas. Crane availability and location are also important to consider.

\subsubsection{Reactor Failure - Transient Flashover}

a. Problem - In August 2003, the drive system tripped offline again due to $3 / 5$ harmonic filter overcurrent. During investigation of the filter bank, it was noted that the phase B reactor on the $3^{\text {rd }}$ harmonic filter had failed. Figure 12 shows the damage to the harmonic filter reactor.

b. Root Cause - Transient overvoltage had bridged through the reactor to ground, establishing an arc that destroyed the lead connection and part of the reactor winding. The transient was attributed to the frequent starting and stopping and the arc-over event to insufficient insulation voltage.

c. Solution - Although the root cause was traced to a transient condition from frequent starting and stopping, the decision was made to change reactor vendors. A new unit was installed in October 2003. Glastic barriers were added on each reactor between the winding and outer legs to increase the installed insulation voltage rating.

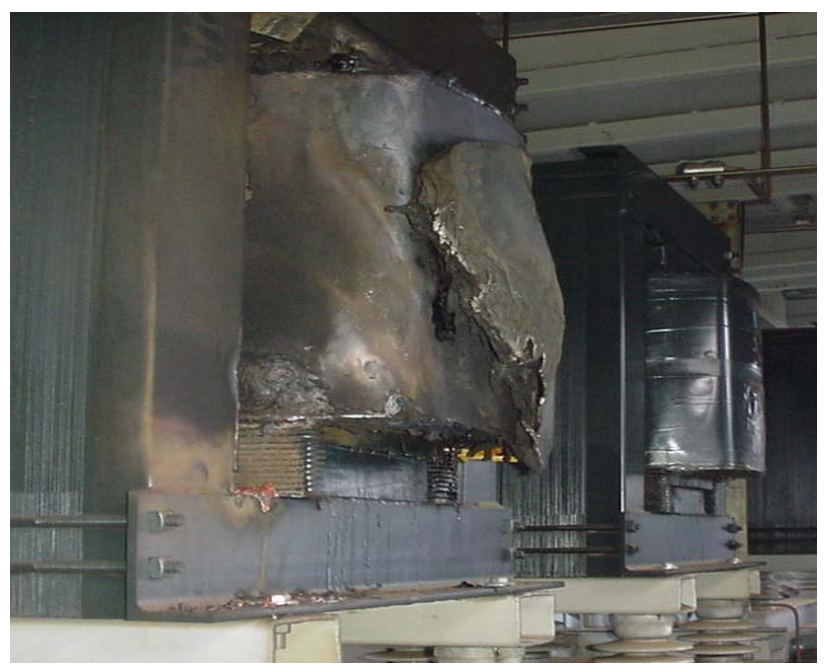

Figure 12: Failed Harmonic Filter Reactor.

d. Lesson Learned - Insulation voltage rating of components can be compromised during installation and use. Conservatism in design and installation is valuable for a long term system installation. 


\subsection{Switchgear}

\subsubsection{Failure of the LCI Line Isolation Switches}

a. Problem - To isolate the stator side of the synchronous motor from electrical power, two motor operated line switches were installed in the switchgear line-up between the transformer secondaries and the input to the LCI line side inverter. These switches were a cost effective solution to breakers (especially since the interrupting capacity was not needed) and were believed to be correctly suited for the application. In December 1998, LCI 89-B line switch failed as the drive system was being isolated. The NTF was operating at a low fan load condition, approximately 0.8 MW, $60 \mathrm{rpm}$, prior to the failure. Personnel in an adjacent building indicated a large explosion had occurred in the switchyard. The LCI 89-B cubicle door had blown off, and the inner metal shield panels had been blown off the right side, consequently scraping into several terminal blocks, shorting them. Metal splatter and arcing throughout the cubicle indicate a phase to phase arc and phase to ground arc had been established. The rear insulating standoffs had been plated with metal plasma when the fault occurred, rendering the insulators useless. Figure 13 shows the damaged switch prior to removal. The decision was made not to replace the insulators, but instead to provide solid copper buswork in place of the switch mechanism as a temporary connection. This would allow research testing to continue while the switches were replaced. Temporary modifications to the control code and the facility operating procedures were required to control isolation of the drive by the main $115 \mathrm{kV}$ circuit breaker upstream of the transformer. The old switch mechanism was removed and the undamaged switch, LCI 89-A, was left in the closed position.

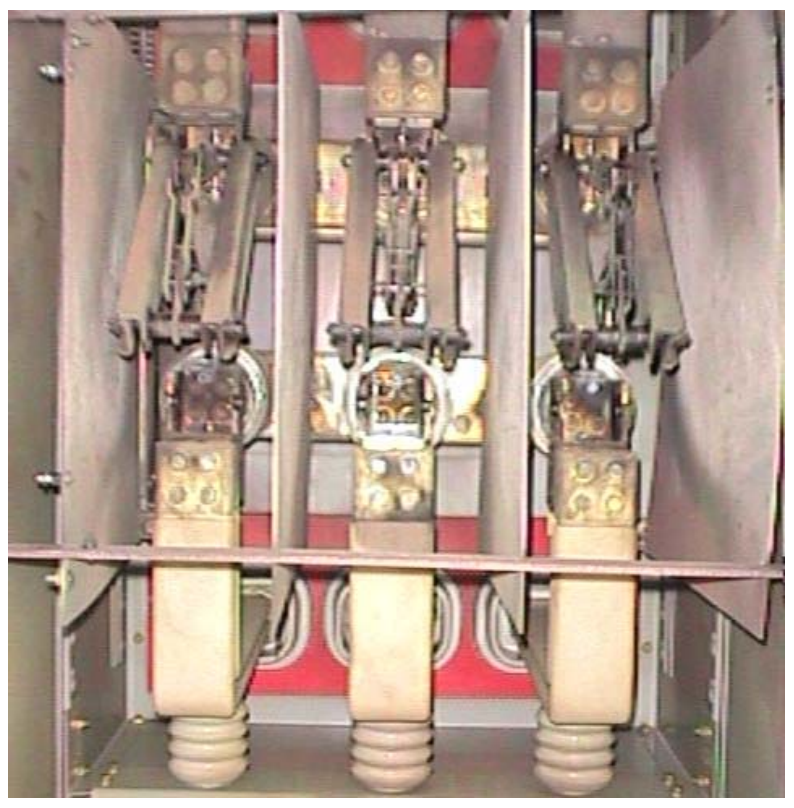

Figure 13: Damaged LCI 89-B line isolator switch

b. Root Cause - Root cause of the fault was determined to be opening the switch with residual capacitive current flowing across the switch contacts. This current flow was a result of the thyristor snubber circuits and leakage currents of the shielded primary feeder cables. The LCI snubber circuit resistor/capacitor networks require 1.5 amps reactive current. The 600' of (4) parallel $1000 \mathrm{kcmil}$ cable runs require another 1.5 amps capacitive leakage current. The switches were designed for zero current opening and cannot open with current flow for two reasons: 1) No arc chutes/blades are provided to protect the main contacts and extinguish the arc, 2) The switches physically do not open fast enough to prevent a re-strike arc from forming. Consequently, an opening of capacitive current can initiate a re-strike phenomenon, ratcheting up the arc voltage indefinitely, causing an ionizing environment within the switch area. This ionized air will then conduct phase to phase or phase to ground current anywhere a path is available. It was also determined that the switches were designed for 250 cycles, and had already exceeded the design life cycle count. These were not designed to handle the higher cycle count required by the wind tunnel application.

c. Solution - The line switches were redesigned and replaced. The new switches included arc chutes, stronger release springs, and mechanical hardware designed for the frequent cycling application. As part of the quality assurance plan, a prototype switch was built, tested to failure, with results incorporated into the production units. Unfortunately, when the switches arrived at the site to be installed, both line switches had very poor insulation readings. The problem was isolated to the switches' fibreglass pushrods, which, from appearance were perfect. A new set of pushrods were installed and the switches have operated successfully since.

d. Lesson Learned - To meet overall system level requirements, traceability to the sub supplier is required. In addition, communication of absolutes, not relatives is important. Zero is sometimes just close to zero. Finally, everything must pass quality assurance inspections, even brand new replacement hardware.

\subsubsection{Breaker Wear out}

a. Problem - By 2008, the frequency of breaker operation was taking a significant toll on the reliability of the harmonic filter and excitation breakers in the switchyard. Several operational failures and an insulator flashover drove the decision to replace the breakers.

b. Root Cause - The breakers were worn out from excessive cycling needed by the wind tunnel application.

c. Solution - New breakers were purchased and installed, the existing breakers were refurbished and kept for spares.

d. Lesson Learned - Reliability can be maintained either through robustness or a well-organized replacement schedule. In this case, it was accepted that the breakers would be used as switching devices; and when reliability reached the threshold of unacceptability, the units were replaced. 


\subsection{Project-Level Lessons}

Each event listed in this paper can be analyzed and specific root causes determined. One can understand, after the failure, what went wrong and see clear ways to make detail-level improvements to preclude the events from occurring again. None of these events were complex technically, but rendered the system non-operational just the same. Beyond the individual actions, there are higher level observations that should be noted as important lessons to apply for every project whether routine or unique.

\subsection{Requirements}

The Owner's requirement documents must include all necessary performance points and limiting constraints that the system is expected to operate within. All conditions, operating modes, influences of subsystems, and owner preferences must be clearly explained. Each requirement must include a measurable acceptance criteria. For desirable performance that is difficult to measure ie - design life, mean time between failure, or cycle rates, innovated ways and drill down into quality control are needed to assure the owner that the requirements are being met. Be prepared to invest in this quality assurance action to achieve the desired performance.

\subsection{Application}

Application specific information defining exactly where and how the system will be used must be given to the system provider. Local ambient conditions, cooling tower design data, power grid harmonic baselines and regulation capability, and load particulars are some of the necessary parameters. Even if determination or measurement of in-situ values are difficult to obtain accurately, it must be done. There is no way a system provider can design and provide a successful solution to an undefined application.

\subsection{System Provider}

Selection of a system provider is critical in the success of any project, but for first time, one of a kind projects, competence and attitude can be deal breaker. The working relationship between the owner and system provider in this case was excellent, and it was clear that both parties were working to achieve the same goals in this project. During the problems that occurred, even after the warranty period, the relationship between owner and system provided remained positive and professional, making the difficult times less of a hardship.

\subsection{Installation}

Many times the installation design gets a lower priority than system performance design. Many reasons (excuses) are given for not developing detailed conduit runs, piping layouts, and equipment foundation details. For the owner, these can jeopardize the overall project success as easily as a poorly designed component. Specifications for installation designs have to be included in the requirement documents early in the solicitation phase to emphasis the importance of this project element. Inspections and quality assurance are equally important in the installation/construction phase to assure that the system is installed as designed.

\subsection{Spare Parts}

Allocations for spare parts can be difficult; unless funds can be justified on downtime cost. For a new and unique system, some components should have a 'burn-in' period to prove the performance prior to purchasing spares. Had spares of the original iron core reactors been procured, they would have been defective as well. For the more common, proven components such as the LCI low voltage supply, a correct spare would have been very prudent. A good approach would be to get low risk spares early on; as well as components that are part of a manufacturing lot.

\subsection{Temporary Solutions}

While production is always the priority, temporary solutions must be carefully thought through and associated risks understood. In the case of the harmonic filter failures, limited operation was a successful work around until the repair was made. For the LCI power supply replacement, it represented a risk that was unacceptable; and the probability that the second power supply would fail so soon was too high. Never forget that a temporary solution increases the probability of a double order failure mode.

\subsection{Warranty}

The NTF drive system was provided with a three year warranty. This extended period was extremely valuable for a unique, custom designed system of this magnitude. Because the drive system had so much intermittent operation, several years were required for the 'infant mortality' type initial failures to occur. The value of this warranty could not have been estimated in the initial project phases. Always consider the warrant period and get the longest one possible.

\section{Summary}

Operation of the world's largest adjustable speed drive in a NASA wind tunnel has been exciting and fulfilling. The capability of the ASD far exceeded the original drive train, and provides capabilities that were not foreseen at the onset of the project.

Many of the problems experienced with the drive system have not been from the technology chosen or materials selected, but with the application challenges of fitting the system into a wind tunnel testing environment. For engineers today, this same challenge remains. Technology changes, but for each application, good planning and design thoughtfulness is a constant requirement. Success of a complex system is only as good as the weakest component, and one must be always vigilant of operational scenarios that indicate a weakness; visualizing how things will work together and what the impacts are when they don't. 


\section{Acknowledgements}

The authors would like to thank the original project team and the National Transonic Facility personnel for making this one-of-a-kind system an integral part of a very unique wind tunnel. The enthusiasm and dedication of these people made the application possible and successful, and we deeply appreciate their contributions to the initial and continued success of the drive system.

\section{References}

[1 Bhatia, Ram, et al., “Adjustable Speed Drive Using a Single 135,000 HP Synchronous Motor”, paper presented at the IEEE International Electrical Machines and Drives Conference, May 1997, pages TC1/9.1 - 9.3

[2] Inge, John T., et al., "Commissioning and Operational Experience for the 135,000 HP Adjustable Speed Drive at NASA's National Transonic Facility”, paper presented at the IEEE Electric Machines and Drives International Conference IEMD '99, May 1999, pages 694 - 697

[3] Popernack, Tom G., et al., "Recent Productivity Improvements to the National Transonic Facility" AIAA 982704, presented at the $20^{\text {th }}$ AIAA Advanced Measurement and Ground Technology Conference, 1998

[4] "IEEE Recommended Practices and Requirements for Harmonic Control in Electric Power Systems," IEEE 5191992

[5] "Design, Furnish and Install a 100-Megawatt Adjustable Speed Drive System for the National Transonic Facility", NASA Langley Research Center, Solicitation 1-64-GGH, 1567, Exhibit A, page 12.

[6] Data compiled from the National Transonic Facility logs, facility TTR/PFR documentation, and personal files of the authors.

[7] Mylius, J, Bonanini, A, Lubasch, R, "NTF Safe Operating Area with Disconnected Filter Components," S105357, June 1998 